\title{
Antidepressants and Driving in Older Adults: A Systematic Review
}

\author{
Duncan H. Cameron and Mark J. Rapoport \\ Sunnybrook Health Sciences Centre; University of Toronto, Department of Psychiatry
}

\begin{abstract}
RÉSUMÉ
Avec le nombre croissant de conducteurs âgés pour lesquelles on prescrit des antidépresseurs, les conséquences potentielles de l'utilisation des antidépresseurs sur les compétences de conduite dans une population vieillissante deviennent un problème urgent. Nous avons effectué une analyse systématique en utilisant MEDLINE, ciblant des articles qui se rapportent spécifiquement aux antidépresseurs et à la conduite dans une population ou sous-groupe de personnes âgées ( $\geq 55$ ans d'âge). La recherche a retourné 267 références, dont neuf portaient sur les effets des antidépresseurs sur la conduite chez les personnes âgées. L'étude expérimentale unique a trouvé que imipramine exerce des effets néfastes sur la conduite sur autoroute, alors que la néfazodone n'a pas fait. Sept des huit études de population ont rapporté une augmentation significative du risque d'être impliqué dans une collision associé à l'utilisation des antidépresseurs. Bien que les études ont indiqué un effet négatif des antidépresseurs sur la conduite, les conceptions épidémiologiques ne peuvent pas exclure la possibilité que la maladie sous-jacente, qui est généralement la dépression majeure, est la coupable.
\end{abstract}

\begin{abstract}
With an increasing number of older drivers who are prescribed antidepressants, the potential consequences of antidepressant use on driving skills in an aging population are becoming a pressing issue. We conducted a systematic review using MEDLINE, targeting articles specifically pertaining to antidepressants and driving in a population or subgroup of older adults ( $\geq 55$ years of age). The search yielded 267 references, nine of which pertained to the effects of antidepressants on driving in older adults. The single experimental study found imipramine to have detrimental effects on highway driving, whereas nefazodone did not. Seven of eight population-based studies reported a significant increased risk of involvement in a collision associated with antidepressant use. Although the studies indicated a negative effect of antidepressants on driving, the epidemiological designs cannot exclude the possibility that the underlying illness, generally major depression, is the culprit.
\end{abstract}

Manuscript received: / manuscrit reçu : 06/09/14

Manuscript accepted: / manuscrit accepté : 11/05/15

Mots clés : vieillissment, accidents de la circulation, antidépresseuses, conduite, collisions automobiles, aînés

Keywords: aging, traffic accidents, antidepressive agents, driving, motor vehicle collisions, seniors, traffic

La correspondance et les demandes de tirés-à-part doivent être adressées à: / Correspondence and requests for offprints should be sent to:

Mark J. Rapoport, M.D.

FG37-2075 Bayview Ave.

Toronto, ON M4N 3M5

(mark.rapoport@sunnybrook.ca)

The association between the prescription of antidepressant medication and the risk of involvement in a motor vehicle collision (MVC) has been examined in recent literature, but very little of this literature focuses on a population of older adults. This is potentially troubling given that antidepressants tend to be highly prescribed among seniors: Between 2007 and 2010, they were prescribed for 17 per cent of individuals aged 65 years and older in America (Centers for Disease
Control and Prevention, 2012). Additionally, the crash rates per 100 million miles across age groups have a bimodal distribution. Whereas younger drivers ( $\leq$ age 29) show high crash rates, an increase in crash rates can be seen to drastically increase at age 70 with the highest likelihood of crash per miles driven being seen in drivers $\geq$ age 85 (8.8 per 100 million miles vs. 1.0 for the 40-44 age group; National Highway Traffic Safety Administration, 2014). 
Many of the past studies on antidepressants and driving demonstrate detrimental effects of antidepressants on motor coordination, reaction time, and attention (Verster \& Ramaekers, 2009; Sansone \& Sansone, 2009) - all elements important for operating a motor vehicle. These antidepressant effects may compound the deficits in visual, cognitive, and motor skills associated with normal aging (Staplin, Gish, \& Wagner, 2003), and the risk of being involved in an MVC increases in later life after adjustment for distance driven (Tefft, 2008).

Depression itself has been related to certain cognitive deficits, many of which can affect driving performance (Bulmash et al., 2006). There is a high co-morbidity between cognitive impairment and depressive disorders, with depression being the most commonly reported psychiatric symptom among patients with mild cognitive impairment (Lyketsos et al., 2002). Conversely, cognitive impairment is common among older adults with major depression, including domains of psychomotor speed, memory, and executive functioning (Morimoto \& Alexopolous, 2013).

A comprehensive analysis of the effects of psychotropic medications on driving performance and outcomes can be found in the Integrated Project DRUID (Driving under the Influence of Drugs, Alcohol and Medicines; Schulze, Schumacher, Urmeew, \& Auerback, 2012); however - as with much of the current literature on driving with the use of psychotropic medications that report did not review the effects of such medications in an elderly population. The purpose of this present study, using a systematic review, was to synthesize the existing literature on the effects of antidepressants on driving in older adults.

\section{Methods}

We conducted a search of MEDLINE, covering dates from 1946 to September 2013, using the following terms: automobile driving, accidents (traffic), motor vehicle collisions, antidepressants or antidepressive agents, depressive disorders. An updated literature search was done in December 2014, upon revision of the manuscript on which this article is based, to ensure the most up-to-date results.

Included articles had to directly address the question of driving and antidepressants, using either an experimental or epidemiological design; a control group was required for inclusion. Editorials, case studies, and letters were excluded, as were studies that did not incorporate a measure of driving or MVCs beyond psychomotor testing. The reference lists of review papers were screened to identify any additional primary papers. After abstract review, we read each of the papers that met all of the above inclusion criteria, and we included only those that reported on a population or subpopulation of older adults. We defined this population as being at least 55 years of age or older in order to guarantee the most inclusive review of the literature, as cutoffs for what constitutes an "older driver" tended to differ among studies (see Table 1).

\section{Results}

We screened a total of 267 articles. Of these, 225 were excluded because they did not address the question of the review, or did not incorporate a driving measure, antidepressants, or comparison group. Of 42 potential studies that we reviewed in detail, one experimental and seven epidemiological studies met inclusion criteria in the initial search, and one additional epidemiological study was found in the updated search (see Figure 1 for the article selection process and Table 2 for a summary of results). Seven of nine of the papers had a minimum cut-off age of 65 , and two had a minimum cut-off age of 60 (Table 1).

\section{Experimental Study}

There was only one experimental study in which investigators assessed the effects of an antidepressant on driving ability in a subgroup of older adults. van Laar, van Willgenburg, and Volkerts (1995) enrolled 12 healthy participants aged 60 and older $(M=65.2$ years, $S D=3.8)$, as well as 12 younger participants $(M=28.2$ years, $S D=4.2$ ), in a randomized crossover study. Participants received one week each of imipramine, $50 \mathrm{mg}$ twice daily; nefazodone, $100 \mathrm{mg}$ twice daily; nefazodone, $200 \mathrm{mg}$ twice daily; and placebo, separated by a 7-day period, in a randomized order, blind to treatment assignment. All participants underwent an on-road driving test on days 1 and 7 of each treatment period. The test consisted of 75 minutes of controlled highway driving, and automated measures were made of the standard deviation of lateral position and standard deviation of

Table 1: Age distribution across studies

\begin{tabular}{lllr}
\hline Study & $\begin{array}{l}\text { Minimum } \\
\text { Age Accepted, } \\
\text { years }\end{array}$ & $\begin{array}{l}\text { Age Range, } \\
\text { years }\end{array}$ & $\begin{array}{l}\text { Mean Age } \\
\text { (SD), years }\end{array}$ \\
\hline Orriols et al. (2013) & 65 & $66-84$ & $71.9(4.6)$ \\
Meuleners et al. (2011) & 60 & $60-80+$ & $75(8.5)$ \\
Coupland et al. (2011)) & 65 & $65-85+$ & $75(7.6)$ \\
Rapoport et al. (2011) & 65 & $66-88$ & $74(6.0)$ \\
Rapoport et al. (2008) & 65 & $\mathrm{~N} / \mathrm{A}$ & $74.9(5.7)$ \\
Hu et al. (1998) & 65 & $\mathrm{~N} / \mathrm{A}$ & $\mathrm{N} / \mathrm{A}$ \\
van Laar et al. (1995) & 60 & $60-72$ & $65.2(3.8)$ \\
Leveille et al. (1994) & 65 & $65-80+$ & $\mathrm{N} / \mathrm{A}$ \\
Ray et al. (1992) & 65 & $65-84$ & $\mathrm{~N} / \mathrm{A}$ \\
\hline
\end{tabular}




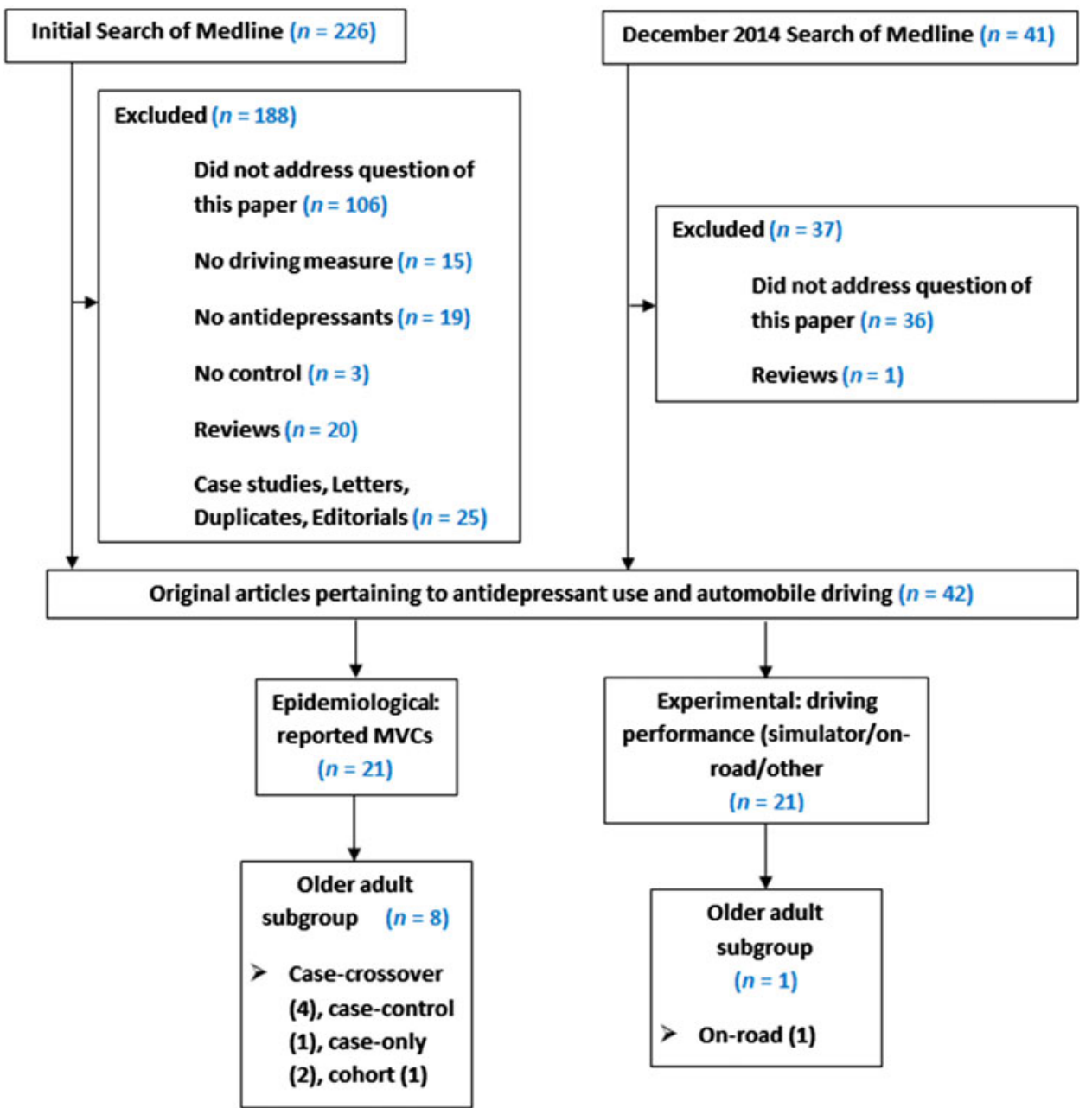

Figure 1: Strategy for selection of relevant articles

speed. The investigators found that neither dose of nefazodone adversely affected either lateral position or speed. Imipramine increased the standard deviation of lateral position the day following the first dose, but only for the younger cohort. On the seventh day of treatment, there were no significant effects of driving measures for the older or younger subgroups on either of the medications, as compared to placebo. The maximum age of the older cohort was 72; one of the older participants was unable to complete the driving measures, and three of them were taking concomitant "peripherally acting medication", although the details of those medications and dosing were not specified.

\section{Epidemiological Studies}

Orriols, Wilchesky, Lagarde, and Suissa (2013) conducted a pair-matched analytical case-crossover study of 109,406 drivers (20.1\% exposed to antidepressants) aged 66-84 during the time period 1988-2000. Antidepressant exposure was compared in 30-day time intervals from the day of the crash to 240 days pre-MVC. Antidepressants were studied inclusively, and in the separate categories of tricyclic antidepressants (TCAs; 62.2\%), selective serotonin reuptake inhibitors (SSRIs; 30.2\%), and all other antidepressants $(9.8 \%)$. The mean age at MVC was $71.9(S D=4.6)$, and 80.5 per cent of the drivers were males. Both new users (those who began taking antidepressants in 30 days prior to MVC) and longer-term users had an increase in $\mathrm{MVC}$ risk (new: $\mathrm{OR}=1.30,95 \% \mathrm{CI}=1.08-1.57$; other users: $\mathrm{OR}=1.49,95 \% \mathrm{CI}=1.35-1.65)$. However, the risk of MVC was higher if antidepressant use was started 8 months before the crash $(\mathrm{OR}=1.42$, $95 \% \mathrm{CI}=1.30-1.55)$ than 4 months before the crash $(\mathrm{OR}=1.19,95 \% \mathrm{CI}=1.08-1.30)$. Results by antidepressant class showed that drivers taking TCAs showed consistently lower ORs compared with SSRIs (at 4 months prior, for example, TCA: $\mathrm{OR}=1.11,95 \% \mathrm{CI}=0.98-1.25$; SSRI: $\mathrm{OR}=1.35,95 \% \mathrm{CI}=1.14-1.60)$.

Meuleners et al. (2011) assessed 616 individuals aged 60 and older who had been hospitalized as a result of 


First Author, Country Design

Total $n$ ( $n$ exposed to Outcome

antidepressants)

Year

Orriols et al. Canada Pair-matched

(2013)

analytical

case-cross-over

Meuleners et al. Australia (2011)

Retrospective

population-based

case-crossover

Coupland et al. United Kingdom Cohort

(2011)

Rapoport et al. Canada (2011)

Rapoport et al. Canada (2008)

Hu et al.

(1998)

van Laar et al. Netherlands 4-way crossover (1995)

Leveille et al. USA

(1994)

Ray et al

(1992)
Population-based, case-only, time-toevent analysis

Population-based case-crossover

Case-only

Population-based matched case-control

Retrospective cohort study
$109,406(21,943) \quad$ Increased risk for a prescription of antidepressants 4 months before the crash $(O R=1.19,95 \% \mathrm{Cl}=1.08-1.30)$ to 8 months before crash $(\mathrm{OR}=1.42,95 \% \mathrm{Cl}=1.30-1.55)$. Risk for new users was not significantly different from risk for all other users (new: $\mathrm{OR}=1.30,95 \% \mathrm{Cl}=1.08-1.57$. other users: $\mathrm{OR}=1.49,95 \% \mathrm{Cl}=1.35-1.65)$

$616(85)$

Greater risk was found for older drivers prescribed $(\mathrm{OR}=1.80,95 \% \mathrm{Cl}=1.00-3.30, p=0.04)$. Crash risk was significant only in older men, not in older women.

419 (167) None of the three classes of antidepressants showed a significantly increased HR for an MVC (TCAs: HR $=0.83$, $95 \% \mathrm{Cl}=0.62-1.11 ; \mathrm{SSRI}$ : $\mathrm{HR}=0.92,95 \% \mathrm{Cl}=0.72-1.16$; others: $\mathrm{HR}=0.71,95 \% \mathrm{Cl}=0.42-1.19$ ).

$159,678(7,393) \quad$ MVC associated with ATDs in month prior to collision. Increase in crash risk significant for 2 nd generation ATDs but not 1 st. Similar risk between men and women. Greatest risk associated with "at-fault" crashes, but not significant for "driving properly" crashes.

Risk of MVC with ATDs in individuals with dementia $(O R=1.82,95 \% \mathrm{Cl}=1.66-2.13)$. Later generation ATDs (SSRIs) assoc. w/ higher risk of MVC (OR $=2.15,95 \% \mathrm{Cl}=1.78-.60)$ than 1 st generation $(O R=1.31,95 \% \mathrm{Cl}=1.07-1.61)$.

882 (not specific) Use of ATDs for males was the strongest risk factor, next to the amount of annual driving (of all crash risks in panel).

The risk of older male drivers who use ATDs being involved in crashes was double that of controls.

24 (24) Nefazodone did not impair highway driving. Imipramine showed detrimental effect on SDLP 24 hours after exposure, but only in younger individuals. Elderly adults seemed to tolerate imipramine better.

Compared with non-users, current users of cyclic antidepressants had an adjusted RR of $2.30(95 \% \mathrm{Cl}=1.10-4.80)$. RR increased with dose, but decreased with length of exposure to the drug.

16,262 (not specific) For cyclic antidepressants ( $R R=2.20 ; 95 \% \mathrm{Cl} 1.30-3.50$ ). RR increased with dose and was substantial for high doses: 2.40 (95\% Cl 1.30-4.40), 5.50 (95\% Cl 2.60-1 1.6) for $\geq 125 \mathrm{mg}$ amitriptyline. Concurrent use of two different ATDs associated with pronounced increase in RR. Risk did not vary with duration of use.
Limitations

No data on dosage or depressive symptom presence/severity. No data on adherence to prescription.

Limited to hospitalized crashes Does not distinguish at-fault status. Did not adjust for time-varying confounders.

Residual confounding due to possible lack of variables from databases.

Inability to assess risks associated with dose or duration of exposure.

Inability to quantify risks with duration of exposure, dose, or adherence.

No data on dose or duration of exposure.

Small sample sizes result in a questionable representation of the elderly population.

Data on daily dose and adherence to prescription was limited.

No information on driving frequency. Inability to distinguish drug effects from possible effects of disorders. Population consisted of Medicaid enrollees only

$\mathrm{ATD}=$ antidepressants, $\mathrm{Cl}=$ confidence interval, $\mathrm{HR}=$ hazard ratio, $\mathrm{MVC}=$ motor vehicle collision, $\mathrm{OR}=$ odds ratio, $\mathrm{RR}=$ relative risk, $\mathrm{SDLP}=\mathrm{standard}$ deviation of latera position, SSRI = selective serotonin reuptake inhibitors, TCA = tricyclic antidepressants. 
involvement in an MVC and had been prescribed a psychoactive medication prior to the collision. A casecrossover design, with multiple time-control intervals, was used, and antidepressant prescription accounted for 13.8 per cent $(n=85)$ of the medications investigated in this study, with the remainder being benzodiazepines and opioids. Antidepressants were not analyzed by class. The authors found an almost doubling of risk of exposure to antidepressants associated with MVCs $(\mathrm{OR}=1.80,95 \% \mathrm{CI}=1.00-3.30, p=.04)$, but the risk was restricted to men.

Coupland et al. (2011) conducted a cohort study with MVCs among a cohort of individuals aged 65 and older. Eleven of the most commonly prescribed antidepressants were identified and were separated by class. The authors identified 167 total MVCs in the cohort, but none of the three classes of antidepressants showed a significantly increased hazard ratio (HR) for an MVC compared to individuals not taking antidepressants (TCAs: $\mathrm{HR}=0.83,95 \% \mathrm{CI}=0.62-1.11$; SSRIs: $\mathrm{HR}=0.92$, $95 \% \mathrm{CI}=0.72-1.16$; others: $\mathrm{HR}=0.71,95 \% \mathrm{CI}=0.42-1.19$ ).

Our group conducted a recent time-to-event, case-only analysis to analyze 159,678 MVCs, in which 7,393 individuals had received a prescription for antidepressants in the month prior to the month of the MVC (Rapoport et al., 2011). We separated the antidepressants into "first generation" (tricyclic antidepressants [TCAs], other cyclic antidepressants, and irreversible monoamine oxidase A inhibitors) and "second generation" (SSRIs and newer antidepressants). Although there was a significantly elevated risk of MVC associated with the overall sample of antidepressants $(\mathrm{HR}=1.07$, $\left.95 \% \mathrm{CI}=1.05-1.10, \chi^{2}=33.40, \mathrm{df}=1, p<0.0001\right)$, in a sensitivity analysis, only second-generation antidepressants showed a significant increase in risk ( $\mathrm{HR}=$ $1.10,95 \% \mathrm{CI}=1.07-1.13, \chi^{2}=41.77, \mathrm{df}=1, p<0.0001$ ). Further, analyses showed that only patients coprescribed both benzodiazepines and strongly anticholinergic drugs showed a significantly increased MVC risk (23\% and 63\%, respectively).

We also conducted an earlier study with a case-crossover design, examining a range of psychotropic medications (which included benzodiazepines, antidepressants, antipsychotics, topical antifungals, and topical corticosteroids) among elderly drivers with dementia. Of the 8,690 total individuals who experienced an MVC, 1,544 $(17 \%)$ were prescribed antidepressants. The combination of dementia and antidepressant medication use yielded an OR of $1.82(95 \% \mathrm{CI}=1.66-2.13)$. In that study, later generation antidepressants, such as SSRIs, were associated with a higher risk of an MVC than first-generation antidepressants such as tricyclic agents $(\mathrm{OR}=2.15,95 \% \mathrm{CI}=1.78-2.60$ vs. $\mathrm{OR}=1.31,95 \% \mathrm{CI}=$ 1.07-1.61) (Rapoport et al., 2008).
$\mathrm{Hu}$, Trumble, Foley, Eberhard, and Wallace (1998) conducted a study involving 1,811 individuals, analysing a wide range of factors that could potentially affect risk of an MVC, including annual miles driven, difficulty extending arms, back pain, living alone, employment status, and history of glaucoma, in addition to antidepressant prescriptions. Antidepressant use was found to be the second-most influential factor contributing to MVC risk, next to annual miles driven. Antidepressant use, however, was only a significant risk for older male drivers $(\mathrm{OR}=2.04, p<0.05)$, with the probability of being involved in an MVC while using antidepressants increasing per annual miles driven (from $\mathrm{P}=0.037$ for 3,000 miles driven to a maximum of $\mathrm{P}=0.069$ for 18,000 miles driven, $p<0.05$ in the older male drivers). Differential antidepressant class effects were not explored.

A 1994 case-control study by Leveille et al. looked at adults aged 65 and older involved in MVCs while prescribed cyclic antidepressants (including largely amitriptyline, doxepin, and imipramine), benzodiazepines, opioid analgesics, or antihistamines. Of the 234 total cases investigated, 23 involved antidepressants. The authors reported a significantly increased risk for involvement in an MVC, with an adjusted relative risk (RR) of 2.30 (95\% CI = 1.10-4.80). The RR increased with dose, but decreased with length of exposure to the drug.

A similar study by Ray, Fought, and Decker in 1992 also investigated the RR of injurious MVC with use of benzodiazepines, antidepressants (mainly amitriptyline, doxepin, imipramine, and trazedone), antihistamines, or opioid analgesics in a sample of 16,262 Medicaid enrollees. Similar to Leveille et al., Ray reported an RR of 2.20 (95\% CI $=1.30-3.50)$. It was also found that the RR increased with increasing dose and concurrent use of more than one antidepressant. For example, for the equivalent of $\leq 25 \mathrm{mg}$ of amitriptyline, the $R R$ was 0.80 $(95 \% \mathrm{CI}=0.10-2.70)$, whereas for $\geq 125 \mathrm{mg}$ the $\mathrm{RR}=$ 5.50 (95\% CI $=2.60-11.6)$. The concurrent use of two or more cyclic antidepressants raised the RR from 2.00 (95\% CI $=1.30-3.10)$ to 9.80 (95\% CI $=2.40-39.5)$. In contrast to the Leveille article, Ray et al. did not find that the risk of involvement in MVC changed with duration of exposure.

\section{Discussion}

Our review of the current literature on the effects of antidepressants on driving performance yielded 39 relevant articles, eight of which included a population or subgroup of older adults. The general findings of each of these studies indicate negative effects of antidepressant use on driving performance, all of which reported an increased MVC risk. Levels of increased risk varied across studies. For context, in 2012 the MVC death rate per 100,000 people aged $65-59$ was 15.6 for males and 
6.1 for females in the United States (National Highway Traffic Safety Administration, 2014). Interestingly, in two of the included studies, the MVC risk associated with antidepressants was restricted to men (Meuleners et al., 2011; Hu et al., 1998). In addition, Rapoport et al. (2011) found that it was not antidepressants alone but those taken in conjunction with other psychoactive drugs which pose a significant risk for older adults.

One of the seven articles we included used an experimental design, with which researchers found that imipramine significantly impaired highway driving performance whereas nefazodone did not. That study contained a small test group of non-depressed veryyoung older adults, so generalizability is limited. Although the study is potentially reassuring regarding the safety of nefazodone and the temporary effects of imipramine on driving, we cannot generalize this finding to a clinical population with depression. Furthermore, imipramine is a medication that is not recommended for older adults (Fick et al., 2012), and nefazodone is no longer available, having been discontinued in North America more than a decade ago due to liver toxicity.

We retrieved six epidemiological studies, dating from 1992 to 2013. The limitations of these studies included lack of reporting on dose and duration (all except Leveille et al., 2011, and Ray et al., 1992), no information on driving exposure (in any), restriction to Medicaid enrollees (Ray et al., 1992), and the lack of adjustment for confounders such as concurrent medication use or ascertainment of MVC at-fault status (except Rapoport et al., 2011). Furthermore, none of the studies reported details of symptoms or treatment of depression, leading to possible indication bias - the potential confusion regarding the true cause of the impaired driving performance. The epidemiological papers acknowledge the challenge of distinguishing between effects on driving outcomes resulting from prescribed antidepressants or from the underlying medical or psychiatric condition, not to mention other potential confounding factors in such non-experimental designs.

Although the epidemiological studies highlighted the possibility of indication bias, only two of them (Coupland et al., 2011; Ray et al., 1992) recognized the two-tailed hypothesis that antidepressant use could improve driving performance. Because cognitive symptoms in depression can impair driving, the effective use of an antidepressant might ameliorate driving skills.

Only three studies analyzed MVC risk by antidepressant class (Orriols et al., 2013; Coupland et al., 2011; Rapoport et al., 2011). This is important as the anticholinergic and sedating properties of older antidepressants such as tricyclics were traditionally viewed as causing more potential impairment from the perspective of road traffic risk, but the newer antidepressants such as SSRIs may pose similar risks. As mentioned earlier, certain TCAs, such as imipramine, are not recommended for use in older adults, but a 2012 update of the Beers Criteria for Potentially Inappropriate Medications has now listed SSRIs as being potentially harmful for older adults as well. Although TCAs can induce anticholinergic effects, SSRIs are cited as having high-quality evidence for fall risk. However, a review by Gebara et al. (2015) concluded that there is insufficient evidence to support this change, at least with respect to falls risk, and concluded that the use of SSRIs as a treatment for depression in older adults should not be discouraged. Moreover, the recent classification of SSRIs as potentially inappropriate medications for older adults might have the unintended consequence of increasing TCA prescriptions, which could also affect driving performance as well as falls. Orriols et al. (2013) also pointed out the risk of exposure misclassification resulting from not monitoring medication adherence, which may be more troublesome with TCAs than newer antidepressants.

An additional difficulty with the bulk of this research is the lack of information on self-regulatory driving behaviour. These studies on driving and psychotropic medication do not take into account how risk homeostasis and task demand homeostasis affect the selfregulation of driving (Fuller, 2005; Wilde, 1982). Michon (1985) proposed an integrated cognitive hierarchical model integrating strategic (planning), tactical (maneuvering), and operational (control) factors. Eby, Molnar, and Kartje (2009, p. 29) proposed a fourth level of "life goals" which might provide additional useful context for older adult driving behaviour. Psychotropic drugs likely exert most of their effect at the tactical level, but because of complexities between pharmacodynamic drug effects and the effects of the underlying condition along with the psychosocial and road environment, other aspects of the model may be affected.

Our initial search for articles pertaining to driving and antidepressants yielded 20 systematic reviews (as Figure 1 shows). Of those reviews, 12 were published in the past 10 years, while the previous eight were published between 1977 and 1997. This does not show a strongly increasing trend and further highlights the dearth of research in this area. Only two of the 20 reviews concentrated specifically on older adults (Ray, Gurwitz, Decker, \& Dennedy, 1992a; Ray, Thapa, \& Shorr,1993), and both were published long ago by the same principal author, showing limited consideration for this particular population thus far in the literature. Most of the studies and reviews did not differentiate between the effects of antidepressant class, and this is a substantial limitation in the literature. 
There is relatively more research concerning younger populations, with 20 reviews on this topic. Five reviews focused specifically on antidepressants and driving (Brunnauer \& Laux, 2013; Orriols et al., 2012; Ravera, Ramaekers, de Jong-van den Berg, \& de Gier, 2012; Rapoport \& Banina, 2007; Ramaekers, 2003; Hale, 1994), whereas the rest looked at a wide range of drugs and/ or other factors in relation to driving. Most articles tended to report that use of the majority of TCAs shows deleterious effects on driving or skills related to driving. Three of these reports (Brunnauer et al., 2013; Ravera et al., 2012, and Hale, 1994) concluded that SSRIs did not appear to impair driving significantly in experimental settings; results are less clear for epidemiological studies, which is consistent with our finding in this article.

There is a growing area of research concerning fitness to drive and the older adult population. In a recent essay, Redelmeier and McLellan (2013) called for a greater focus on MVCs, and highlighted some of the issues surrounding the topic including (a) denial of aggregate statistics, (b) conflicting economic priorities, and (c) inescapable research limitations. The fact that we retrieved only nine primary studies for the present study highlights a substantial gap in research.

A limitation of our review is that we consulted only MEDLINE for article retrieval. Although additional databases could increase the breadth of relevant results, none of the reference lists of the reviews and empiric papers that we manually consulted identified references missed by the MEDLINE search.

The current lack of knowledge and research regarding the potential effects of antidepressant use on driving performance among older adults emphasized in our review points to a clear path for future study. The research that exists on this topic featuring an older age group is not yet extensive enough to validly generalize to a larger population. Therefore, further epidemiological and experimental research, with more diverse elderly adult samples, both volunteer and clinical, would be expedient.

\section{References}

Brunnauer, A., \& Laux, G. (2013). The effects of most commonly prescribed second generation antidepressants on driving ability: A systematic review: 70th Birthday Prof. Riederer. Journal of Neural Transmission, 120(1), 225-232.

Bulmash, E. L., Moller, H. J., Kayumov, L., Shen, J., Wang, X., \& Shapiro, C. M. (2006). Psychomotor disturbance in depression: assessment using a driving simulator paradigm. Journal of Affective Disorders, 93(1-3), 213-218.

Centers for Disease Control and Prevention (CDC). (2012). National Center for Health Statistics (NCHS). National Health and Nutrition Examination Survey Data. Hyattsville, MD: U.S. Department of Health and Human Services.
Coupland, C., Dhiman, P., Morriss, R., Arthur, A., Barton, G., \& Hippisley-Cox, J. (2011). Antidepressant use and risk of adverse outcomes in older people: Population based cohort study. BMJ, 343, d4551. doi:10.1136/bmj.d4551

Eby, D. W., Molnar, L. J., \& Kartje, P. S. (2009). Maintaining safe mobility in an aging society. Boca Raton, FL: CRC Press.

Schulze, H., Schumacher, M., Urmeew, R., \& Auerbach, K. (2012). Final Report: Work performed, main results and recommendations. DRUID (Driving under the Influence of Drugs, Alcohol and Medicines) Deliverable 0.1, 8. Retrieved from http:/ / www.druid-project.eu/ (Accessed January 2015).

Fick, D., Semla, T., Beizer, J., Brandt, N., Dombrowski, R., BuBeau, et al. (2012). American Geriatrics Society updated Beers Criteria for potentially inappropriate medication use in older adults. Journal of the American Geriatrics Society, 60(4), 616-631.

Fuller, R. (2005). Towards a general theory of driver behaviour. Accident Analysis and Prevention, 37(3), 461-472.

Gebara, M. A., Lipsey, K. L., Karp, J. F., Nash, M. C., Iaboni, A., \& Lenze, E. J. (2015). Cause or effect? Selective serotonin reuptake inhibitors and falls in older adults: A systematic review. The American Journal of Geriatric Psychiatry, 23(10), 1016-1028.

Hale, A. S. (1994). The importance of accidents in evaluating the cost of SSRIs: A review. International Clinical Psychopharmacology, 9(3), 195-201.

Hu, P. S., Trumble, D. A., Foley, D. J., Eberhard, J. W., \& Wallace, R. B. (1998). Crash risks of older drivers: A panel data analysis. Accident Analysis and Prevention, 30(5), 569-581.

Leveille, S. G., Buchner, D. M., Koepsell, T. D., McCloskey, L. W., Wolf, M. E., \& Wagner, E. H. (1994). Psychoactive medications and injurious motor vehicle collisions involving older drivers. Epidemiology, 5(6), 591-598.

Lyketsos, C. G., Lopez, O., Jones, B., Fitzpatrick, A. L., Breitner, J., \& DeKosky, S. (2002). Prevalence of neuropsychiatric symptoms in dementia and mild cognitive impairment: results from the cardiovascular health study. Journal of the American Medical Association, 288(12), 1475-1483.

Meuleners, L. B., Duke, J., Lee, L. H., Palamara, P., Hildebrand, J., \& Ng, J. Q. (2011). Psychoactive medications and crash involvement requiring hospitalization for older drivers: A population-based study. Journal of the American Geriatrics Society, 59(9), 1575-1580.

Michon, J. A. (1985). A critical view of driver behavior models: What do we know, what should we do? (pp. 485-525). New York, NY: Springer.

Morimoto, S. S., \& Alexopolous, G. S. (2013). Cognitive deficits in geriatric depression: Clinical correlates and implications for current and future treatment. Psychiatric Clinics of North America, 36(4), 517-531. 
National Highway Traffic Safety Administration. (2014). Traffic safety facts: A compilation of motor vehicle crash data from the Fatality Analysis Reporting System and the General Estimates System. Retrieved from http: / / www-nrd.nhtsa.dot.gov / Cats / listpublications.aspx? Id=E\&ShowBy=DocType (Accessed January 2015).

Orriols, L., Queinec, R., Philip, P., Gadegbeku, B., Delorme, B., Moore, N., et al. (2012). Risk of injurious road traffic crash after prescription of antidepressants. Journal of Clinical Psychiatry, 73(8), 1088-1094.

Orriols, L., Wilchesky, M., Lagarde, E., \& Suissa, S. (2013). Prescription of antidepressants and the risk of road traffic crash in the elderly: A case-crossover study. British Journal of Clinical Pharmacology, 76(5), 810-815.

Ramaekers, J. G. (2003). Antidepressants and driver impairment: Empirical evidence from a standard on-the-road test. Journal of Clinical Psychiatry, 64(1), 20-29.

Rapoport, M. J., \& Banina, M. C. (2007). Impact of psychotropic medications on simulated driving: A critical review. CNS Drugs, 21(6), 503-519.

Rapoport, M. J., Herrmann, N., Molnar, F., Rochon, P. A., Juurlink, D. N., Zagorski, B., et al. (2008). Psychotropic medications and motor vehicle collisions in patients with dementia. Journal of the American Geriatrics Society, 56(10), 1968-1970.

Rapoport, M. J., Zagorski, B., Seitz, D., Herrmann, N., Molnar, F., \& Redelmeier, D. A. (2011). At-fault motor vehicle crash risk in elderly patients treated with antidepressants. American Journal of Geriatrics Psychiatry, 19(12), 998-1006.

Ravera, S., Ramaekers, J. G., de Jong-van den Berg, L. T., \& de Gier, J. J. (2012). Are selective serotonin reuptake inhibitors safe for drivers? What is the evidence? Clinical Therapeutics, 34(5), 1070-1083.

Ray, W. A., Fought, R. L., \& Decker, M. D. (1992). Psychoactive drugs and the risk of injurious motor vehicle crashes in elderly drivers. American Journal of Epidemiology, 136(7), 878-883.

Ray, W. A., Gurwitz, J., Decker, M. D., \& Kennedy, D. L. (1992a). Medications and the safety of the older driver. Human Factors, 34(1), 33-47.

Ray, W. A., Thapa, P. B., \& Shorr, R. I. (1993). Medications and the older driver. Clinics in Geriatric Medicine, 9(2), 413-438.

Redelmeier, D. A., \& McLellan, B. A. (2013). Modern medicine is neglecting road traffic crashes. PLoS Medicine, 10(6), e1001463.

Sansone, R. A. \& Sansone, L. A. (2009). Driving on antidepressants: Cruising for a crash? Psychiatry, 6, 13-16.

Staplin, L., Gish, K., \& Wagner, E. (2003). MaryPODS revisited: Updated crash analysis and implications for screening program implementation. Journal of Safety Research, 3(4), 389-397.

van Laar, M. W., van Willgenburg, A. P., \& Volkerts, E. R. (1995). Acute and subchronic effects of nefazodone and imipramine on highway driving, cognitive functions, and daytime sleepiness in healthy adult and elderly subjects. Journal of Clinical Psychopharmacology, 15(1), 30-40.

Verster, J. C., \& Ramaekers, J. G. (2009). Antidepressants and traffic safety. In J. C. Verster, S. R. Pandi-Perumal, J. G. Ramaekers, J. J. de Gier (Eds.), Drugs, Driving and Traffic Safety. Basel-Boston-Berlin, Switzerland: Birkaeuser Verlag AG.

Wilde, G. J. (1982). The theory of risk homeostasis: Implications or safety and health. Risk analysis, 2(4), 209-225. 